\title{
Study of supercapacitor ageing and lifetime estimation according to voltage, temperature and RMS current
}

\author{
P. KRECZANIK, P. VENET, A. HIJAZI, G. CLERC
}

\begin{abstract}
Due to its capacity to store or supply energy with high power, the supercapacitor is becoming an attractive component. Because of the electrostatic nature of energy storage, the endurance of this component toward repetitive charge and discharge cycles is relatively high. The goal of this paper is to demonstrate that the cycling has an impact on the degradation of the supercapacitor and as a result on its lifetime. Based on accelerated cycling tests, some supercapacitors were studied using a dedicated test bench. Temperature, voltage, and current, that are the parameters which accelerate ageing, are monitored. In fact, observations during cycling tests show an important acceleration of the degradation compared to a similar static test having the same voltage and core temperature but without cycling. This paper proposes a method to quantify the acceleration of ageing during cycling phase.
\end{abstract}

Keywords - Supercapacitor; ultracapacitor; electrochemical double layer capacitor; calendar test; cycling test; lifetime; accelerated ageing; ageing law.

\section{INTRODUCTION}

The lifetime and reliability of storage systems are important factors to determine the feasibility of electromobility solution. In this study, the target application concerns the supply of trolleybuses. It is characterized by the presence of quasipermanent electric air source, often not reversible providing power to the trolley. The addition of on-board storage system gives the possibility to recover braking energy and fed up trolleybus in case of electrical microcuts which occurs frequently due to different reasons like the presence of insulator, the vibration of trolley's poles, ...

The duration of electrical cuts is relatively small so that the amount of energy to be embarked is low compared to the operating power induced by the equivalent weight of the trolleybus (taking into account the slope of the road). Supercapacitors are potentially interesting to meet these specifications because of their high specific power and good endurance toward cycling. Different works in literature have studied the influence of temperature and voltage on the ageing of supercapacitors [1-5]. However in our paper, we seek to introduce additional factor, which is the effective current, to represent the effect of cycling on the lifetime of the system [6$10]$.

This paper is organized as following:

In the first part, we introduce the test bench used and all cycling tests that are performed in this study. After that, a method is proposed to characterize ageing of supercapacitors during cycling. Finally, a simple thermal model is developed to deduce the temperatures of components.

In the second part, we use the results provided by manufacturer to deduce the equation of lifetime as a function of voltage and temperature. From this equation, we deduce what we call "equivalent calendar degradation" that estimate the ageing of components with respect to the evolution of both temperature and voltage.

The third part presents certain results obtained during cycling. The comparison between the degradations observed during experience and those estimated by "equivalent calendar degradation" shows an important acceleration of ageing caused by cycling.

The fourth part makes an overview about the factors that need to be added to the "equivalent calendar degradation" in order to accurately represent the degradation during cycling. New ageing law which includes the effect of RMS current and by consequence of cycling is proposed and discussed.

\section{GENERAL PRESENTATION OF THE TEST BENCH}

\section{A. Test bench presentation}

The test bench is composed of a power supply, a data acquisition system and a pack of 4 supercapacitors in series. Fig. 1 shows these different elements.

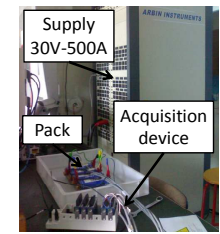

(a) Test bench

Fig. 1: Photo of the test bench

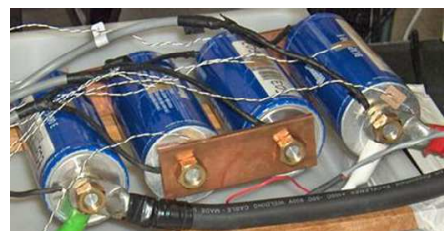

(b) supercapacitors of one pack 
Based on their manufacturer datasheet, each component supports a rated voltage $(\mathrm{Vr})$ of $2.7 \mathrm{~V}$ for a capacitance $(\mathrm{C} 0)$ of $3000 \mathrm{~F}$ and an ESR (Equivalent Series Resistance; R0) of $0,27 \mathrm{~m} \Omega$. No charge balancing device was implemented on purpose to decrease the voltage dispersion between components during cycling tests.

Five packs of 4 serial supercapacitors were cycled (Table I). At least two measurements are provided for each component: terminal voltage and case temperature. For some components, the terminal temperature has also been measured (Fig. 1b).

All packs are charged and discharged with a constant power. Fig. 2 shows the current and voltage profiles for a constant power of $2600 \mathrm{~W}$. The voltage across the stack are limited between $5.4 \mathrm{~V}(=4 . \mathrm{Vr} / 2)$ and $10.8 \mathrm{~V}(=4 . \mathrm{Vr})$ (Fig.2).

After each charge and discharge cycle, a break phase is added. In this phase, the current decreases to zero and by consequence the power is null. The durations of this break time are equal to $t_{\text {break1 }}$ and $t_{\text {break2 }}$ corresponding to the break phase after charge or discharge cycles. These duration, that are chosen to be identical $\left(t_{\text {break } 1}=t_{\text {break } 2}\right)$, determines mainly the RMS current and therefore the heating of supercapacitors. The first four packs were cycled in the ambient air with free convection in an air conditioned room at $24^{\circ} \mathrm{C}$. The last one took place in a climatic chamber at $10^{\circ} \mathrm{C}$ under forced convection. This allows to increase the RMS current without exceeding the maximum core temperature.

TABLE I. CYCLING CONFIGURATION TABLE

\begin{tabular}{|c|c|c|c|c|c|}
\hline \multirow{2}{*}{$\begin{array}{c}\text { Cycling } \\
\text { configuration }\end{array}$} & \multicolumn{3}{|c|}{ Input parameters } & \multicolumn{2}{c|}{$\begin{array}{c}\text { Others } \\
\text { parameters }\end{array}$} \\
\cline { 2 - 6 } & $\begin{array}{c}\text { Charge/Discharge } \\
\text { Power }\end{array}$ & $T_{\text {amb }}$ & $\begin{array}{c}\boldsymbol{t}_{\text {break }} \\
(1 \text { or 2) }\end{array}$ & $\left\langle I_{R M S}\right\rangle$ & $\left\langle\theta_{m}\right\rangle$ \\
\hline Pack 1 & $\mathrm{P}=2600 \mathrm{~W}$ & $24{ }^{\circ} \mathrm{C}$ & $22.5 \mathrm{~s}$ & $158 \mathrm{~A}$ & $63{ }^{\circ} \mathrm{C}$ \\
\hline Pack 2 & $\mathrm{P}=2600 \mathrm{~W}$ & $24{ }^{\circ} \mathrm{C}$ & $40.7 \mathrm{~s}$ & $122 \mathrm{~A}$ & $42{ }^{\circ} \mathrm{C}$ \\
\hline Pack 3 & $\mathrm{P}=2600 \mathrm{~W}$ & $24{ }^{\circ} \mathrm{C}$ & $31.1 \mathrm{~s}$ & $148 \mathrm{~A}$ & $47^{\circ} \mathrm{C}$ \\
\hline Pack 4 & $\mathrm{P}=2000 \mathrm{~W}$ & $24{ }^{\circ} \mathrm{C}$ & $17.6 \mathrm{~s}$ & $159 \mathrm{~A}$ & $45^{\circ} \mathrm{C}$ \\
\hline Pack 5 & $\mathrm{P}=2600 \mathrm{~W}$ & $10^{\circ} \mathrm{C}$ & $12.4 \mathrm{~s}$ & $197 \mathrm{~A}$ & $22{ }^{\circ} \mathrm{C}$ \\
\hline
\end{tabular}

$<\mathrm{I}_{\mathrm{RMS}}>$ and $\left\langle\theta_{\mathrm{m}}>\right.$ are the mean value respectively of RMS current and case temperature measured during all cycling test.

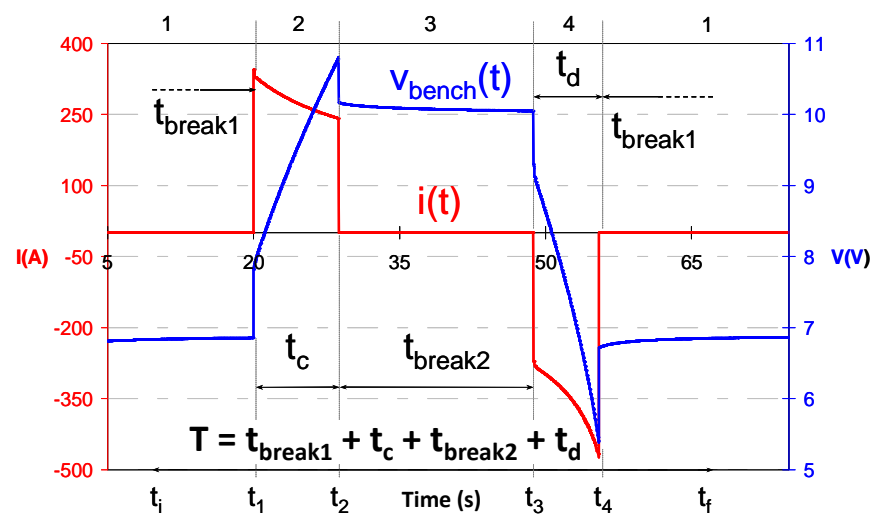

Fig. 2: Power cycling profile $(2600 \mathrm{~W})$

\section{B. Characterization method}

The manufacturer determines the ESR of the components based on the variation of the voltage caused by the extinction of discharge current (2) [7]. As far as the capacity are concerned, it is calculated based on the amount of charge delivered at a constant discharge current and the corresponding voltage variation (4). Our method is the same as the manufacturer method by taking into consideration the parameters that are determined in charge phase of the component (1) (3). Fig.3 illustrates the characterization method.

$$
\begin{gathered}
R_{c}=\left|\frac{V_{c_{-} \max }-V_{c_{-} f}}{I_{c_{-} \min }}\right|=\left|\frac{\Delta V_{R_{c}}}{I_{c_{-} \min }}\right| \\
R_{d}=\left|\frac{V_{d_{-} \min }-V_{d_{-} f}}{I_{d_{-} \max }}\right|=\left|\frac{\Delta V_{R d}}{I_{d_{-} \max }}\right| \\
C_{c}=\frac{\int_{t 1}^{t 2} i(t) d t}{V\left(t_{2}+5\right)-V\left(t_{1}\right)}=\frac{Q_{c_{1}}}{V_{c_{-} f}-V_{c_{-} \min }} \\
C_{d}=\frac{\int_{t 3}^{t 4} i(t) d t}{V\left(t_{3}\right)-V\left(t_{4}+5\right)}=\frac{Q_{d}}{V_{d_{-} \max }-V_{d_{-} f}}
\end{gathered}
$$

Due to the difficulties to present all the results for each component, we present only the average of the measured parameters as following:

$$
\begin{gathered}
R_{m}=\frac{R_{c}+R_{d}}{2} \\
C_{m}=\frac{C_{c}+C_{d}}{2}
\end{gathered}
$$

With: $R_{m}$ the measured equivalent series resistance $[\Omega], C_{m}$ the measured capacitance $[\mathrm{F}]$.

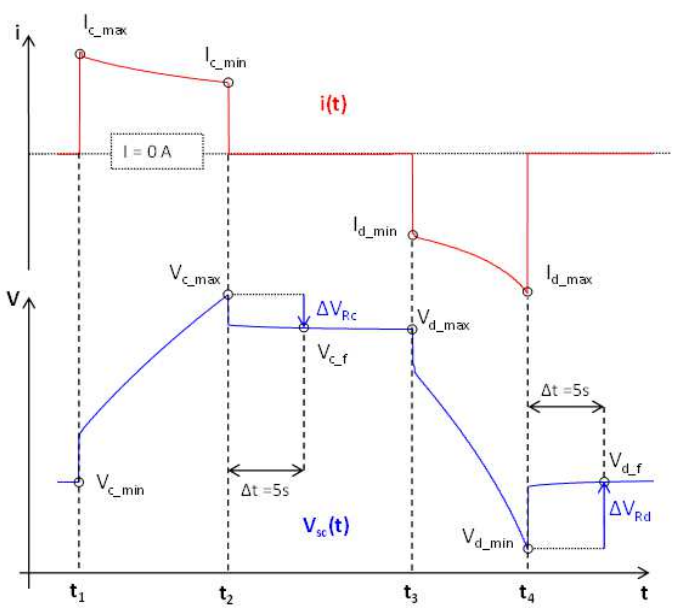

Fig. 3 : Specifics points on cycle charge/discharge with their notations 


\section{Thermal model}

To estimate the core and case temperatures of components, we have used and characterized a simplified thermal model as presented in fig.4 [11]:

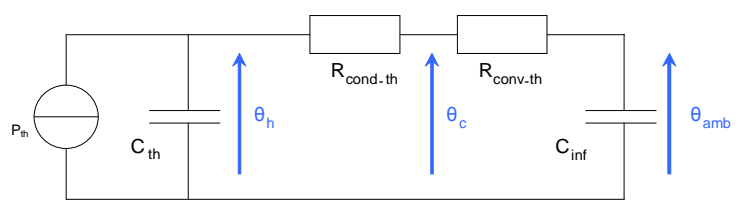

Fig. 4: Thermal model

- $\mathrm{C}_{\mathrm{th}}$ is the thermal capacity of supercapacitors (J.K $\left.\mathrm{K}^{-1}\right)$. The voltage $\left(\theta_{\mathrm{h}}\right)$ across it represents the temperature at the core (or heart) of the component.

- $\mathrm{R}_{\text {cond-th }}$ is the thermal resistor which represents the

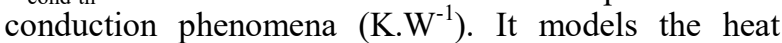
transfer from the core of the component to its case.

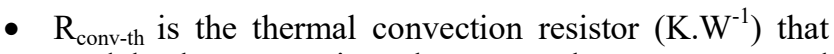
models the convection phenomena between case and ambient temperature.

- $\mathrm{C}_{\mathrm{inf}}$ is the thermal capacity of external environment $\left(\mathrm{J} . \mathrm{K}^{-1}\right)$. It is considered as infinite when the ambient temperature is constant.

- $\mathrm{P}_{\text {th }}$ is the heat dissipation by Joule effect (W). It is supposed to be equal to all losses during charge/discharge cycle, so that:

$$
P_{t h}=\frac{\int_{t_{i}}^{t_{f}} V(t) \times i(t) d t}{\left(t_{f}-t_{i}\right)}=\frac{\int_{t_{c}} V(t) \times i(t) d t+\int_{t_{d}} V(t) \times i(t) d t}{T}=\frac{E_{\text {charge }}-E_{\text {discharge }}}{T}(7)
$$

with $\mathrm{P}_{\text {th }}$ the thermal power losses $[\mathrm{W}], \mathrm{E}_{\text {charge }}$ and $\mathrm{E}_{\text {discharge }}$ respectively the absolute value of the charging and discharging energy $[\mathrm{J}], \mathrm{t}_{\mathrm{f}}$ and $\mathrm{t}_{\mathrm{i}}$ the final and initial time [s] (cf. Fig.2).

For the parameters identification, 150 charge/discharge cycles of $100 \mathrm{~A}$ were applied to one component, without break time, and under free convection. The ambient temperature is stabilized to $24^{\circ} \mathrm{C}\left(\theta_{\mathrm{amb}}=24^{\circ} \mathrm{C}\right)$ via air conditioner $\left(\mathrm{C}_{\mathrm{inf}}\right.$ equal to infinity). The temperature of the terminal has been assumed to be equal to the temperature inside the supercapacitor due to the good thermal conduction between core and case of the component [11-12]. The following Fig.5 and Table II resume the obtained results:

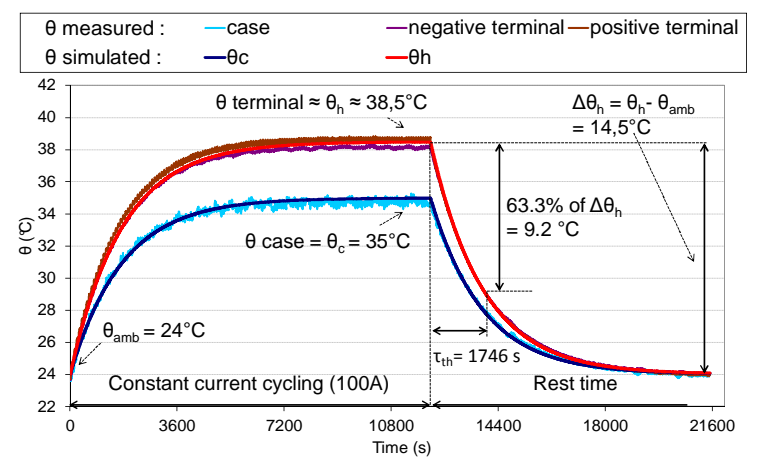

Fig. 5: Measured and simulated temperature.
TABLE II. PARAMETERS OF THERMAL MODEL

\begin{tabular}{|c|c|c|}
\hline \multicolumn{3}{|c|}{ Thermal model identification results } \\
\hline Definitions & Numerical application $^{a}$ & Unit \\
\hline$R_{c o n d-t h}=\frac{\theta_{h}-\theta_{c}}{P_{t h}}$ & $\frac{38,5-35}{6.2}=0.565$ & K.W $\mathrm{W}^{-1}$ \\
\hline$R_{c o n v-t h}=\frac{\theta_{c}-\theta_{a m b}}{P_{t h}}$ & $\frac{35-24}{6.2}=1.77$ & K. W ${ }^{-1}$ \\
\hline$C_{t h}=\frac{\tau_{t h}}{R_{c o n d-t h}+R_{c o n v-t h}}$ & $\frac{1750}{2.34}=748$ & J.K $\mathrm{K}^{-1}$ \\
\hline
\end{tabular}

a. The mean value of $\mathrm{P}_{\mathrm{th}}$ is $6.2 \mathrm{~W}$ (measured for each cycle)

To model the thermal behavior of supercapacitor inside the climatic chamber, only the convection resistor has to be reevaluated. The steady state temperatures measured during tests in the climatic chamber allows us to deduce the

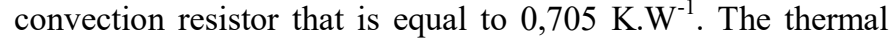
model induces some error due to the fact that it doesn't take into account the position of the supercapacitor inside the packs. However it has been used to estimate the core temperature of component under cycling test.

\section{CALENDAR EQUIVALENT DEGRADATION LAW}

To obtain the "calendar equivalent degradation" law, calendar tests were performed. These tests consist of applying different constants voltage and temperature to component and monitoring the electrical parameters variation. This method quantifies the influence of both temperature and voltage on the lifetime.

\section{A. Datasheet calendar test result}

In calendar test, the climatic chamber temperature $(\theta)$ is equal to the case and the core temperature of supercapacitor (respectively $\theta_{\mathrm{c}}$ and $\theta_{\mathrm{h}}$ ). Maxwell datasheet for the calendar test gives data presented in table III [13]:

TABLE III. END OF LIFE FOR MANUFACTURER DATA

\begin{tabular}{|c|c|c|}
\hline \multirow{2}{*}{ Datasheet end of life } & \multicolumn{2}{|c|}{ Voltage across the supercapacitor } \\
\cline { 2 - 3 } & $2.7 \mathrm{~V}$ & $2.5 \mathrm{~V}$ \\
\hline \multirow{2}{*}{ Chamber temperature: } & \multicolumn{2}{|c|}{ End of life: $^{b}$} \\
\hline$\theta=65^{\circ} \mathrm{C}$ & $3670 \mathrm{~h}$ & $7330 \mathrm{~h}$ \\
\hline$\theta=55^{\circ} \mathrm{C}$ & $7330 \mathrm{~h}$ & $14700 \mathrm{~h}$ \\
\hline$\theta=45^{\circ} \mathrm{C}$ & $14700 \mathrm{~h}$ & $29300 \mathrm{~h}$ \\
\hline$\theta=35^{\circ} \mathrm{C}$ & $2930 \mathrm{~h}$ & $58700 \mathrm{~h}$ \\
\hline$\theta=25^{\circ} \mathrm{C}$ & $58700 \mathrm{~h}$ & $117000 \mathrm{~h}$ \\
\hline
\end{tabular}

We can note that the lifetime is reduced by half when the temperature is increased by $10{ }^{\circ} \mathrm{C}$ or the applied voltage by 
$0.2 \mathrm{~V}$ [13-14]. Assuming this trend, we can establish a relation between the lifetime and voltage and temperature [9-10]:

$$
\tau_{s}(V ; \theta)=\tau_{0} \exp \left(-\frac{V}{V_{0}}-\frac{\theta}{\theta_{0}}\right)
$$

with $\tau_{\mathrm{s}}$ is the static lifetime [s], $\mathrm{V}$ is the constant voltage across the supercapacitor terminals [V] and $\theta$ the climatic chamber temperature $\left[{ }^{\circ} \mathrm{C}\right]$.

Numerical application gives:

$$
\tau_{0}=1.4 \times 10^{13}[s] ; \quad V_{0}=\frac{0.2}{\ln (2)}[V] ; \quad \theta_{0}=\frac{10}{\ln (2)}\left[{ }^{\circ} \mathrm{C}\right]
$$

The equation (8) is deduced from Arrhenius law generalized to two variables [17].

\section{B. Extrapolation of calendar results}

We suppose that the ageing of supercapacitor is directly depending on the redox reaction rate. So for constant voltage and temperature, the redox reaction rate is considered as constant.

This hypothesis is consistent with the curves presented by the manufacturer which shows a linear variation of the capacitance and ESR during calendar ageing (except at the beginning and at the end of the test) [18]. The inverse of the lifetime is therefore homogeneous to a degradation rate of the component $\left[\% . \mathrm{s}^{-1}\right]$. If the voltage and the temperature were the only parameters that influence the deterioration of the component, this variable, homogeneous to the degradation rate of the component, may be expressed using the following equation:

$$
v_{d}(V ; \theta)=\frac{1}{\tau_{s}(V ; \theta)}=\frac{1}{\tau_{0} \exp \left(-\frac{V}{V_{0}}-\frac{\theta}{\theta_{0}}\right)}=\frac{1}{\tau_{0}} \exp \left(\frac{V}{V_{0}}+\frac{\theta}{\theta_{0}}\right)
$$

with $\mathrm{v}_{\mathrm{d}}$ the calendar degradation speed $\left[\% . \mathrm{s}^{-1}\right]$

For a dynamic voltage and/or temperature, the rate of the redox reaction is not constant so the mean value of the reaction rate must be used to estimate the lifetime. Considering that the lifetime is directly proportional to the inverse of reaction rate, the lifetime equation to be used becomes [15-16]:

$$
\tau_{d}(V(t) ; \theta(t))=\frac{1}{\frac{1}{t_{\text {end }}-t_{\text {init }}} \int_{t_{\text {tinit }}}^{t_{\text {end }}} v_{d}(V(t) ; \theta(t)) d t}=\frac{t_{\text {end }}-t_{\text {init }}}{\frac{1}{\tau_{0}} \int_{t_{\text {init }}}^{t_{\text {end }}} \exp \left(\frac{V(t)}{V_{0}}+\frac{\theta(t)}{\theta_{0}}\right) d t}
$$

with $\tau_{\mathrm{d}}$ the dynamic lifetime [s], $\mathrm{V}(\mathrm{t})$ dynamic voltage value across the supercapacitor [V] and $\theta(\mathrm{t})$ dynamic considerate temperature $\left[{ }^{\circ} \mathrm{C}\right], \mathrm{t}_{\mathrm{init}}$ and $\mathrm{t}_{\text {end }}$ are respectively the beginning time and the end time of the entire test [s].

If the cycling test is a succession of $\mathrm{n}$ cycles of period $\mathrm{T}$ and of index " $i$ " having the same voltage and temperature, the study of a single cycle is sufficient to identify an average speed of degradation and thus the lifetime of the components is shown in the following equation:

$$
\tau_{d}(V(t) ; \theta(t))=\frac{1}{\frac{1}{n T} \sum_{i=1}^{i=n} \int_{(i-1) T}^{i T} v_{d}(V(t) ; \theta(t)) d t}=\frac{1}{\frac{n}{n T} \int_{(i-1) T}^{i T} v_{d}(V(t) ; \theta(t)) d t}=\frac{1}{\left\langle v_{d}\right\rangle_{i}}=\left\langle\tau_{d}\right\rangle_{i}
$$

with $\left\langle\mathrm{v}_{\mathrm{d}}\right\rangle_{\mathrm{i}}$ a homogenate value of the mean calendar degradation speed during the cycle "i" $\left[\% . \mathrm{s}^{-1}\right]$ and $\left\langle\tau_{\mathrm{d}}\right\rangle_{\mathrm{i}}$ the equivalent lifetime [s].

This law is used to quantify the "equivalent calendar degradation" of the capacity or ESR for a given cycle. Indeed, if we consider a linear variation of parameters and supposing that the lifetime (decrease of capacity of $20 \%$ and increase of $100 \%$ of ESR) of the component is $\tau_{\mathrm{d}}$, the degradation for one cycle could be estimated as following:

$$
\begin{gathered}
\Delta C_{i}=\frac{-0,2 \times C_{0}}{\left.<\tau_{d}\right\rangle_{i}} T \\
\Delta R_{i}=\frac{R_{0}}{\left.<\tau_{d}\right\rangle_{i}} T
\end{gathered}
$$

with $\Delta \mathrm{C}_{\mathrm{i}}$ and $\Delta \mathrm{R}_{\mathrm{i}}$ are respectively the equivalent calendar degradation of capacitance $[F]$ and ESR $[\Omega]$ for the cycle "i".

To estimate the capacity and ESR of components solicited by $n$ cycle, we have to make the sum of the degradation as shown in the following equations:

$$
\begin{aligned}
& C_{\mathrm{deg}}(n)=\sum_{i=1}^{i=n} \Delta C_{i}=\sum_{i=1}^{i=n}-0,2 \times C_{0} \times \frac{1}{\tau_{0}} \int_{(i-1) T}^{i T} \exp \left(\frac{V(t)}{V_{0}}+\frac{\theta(t)}{\theta_{0}}\right) d t \\
& R_{\mathrm{deg}}(n)=\sum_{i=1}^{i=n} \Delta R_{i}=\sum_{i=1}^{i=n} R_{0} \times \frac{1}{\tau_{0}} \int_{(i-1) T}^{i T} \exp \left(\frac{V(t)}{V_{0}}+\frac{\theta(t)}{\theta_{0}}\right) d t
\end{aligned}
$$

with $\mathrm{C}_{\text {deg }}$ and $\mathrm{R}_{\mathrm{deg}}$ are the "calendar equivalent degradation" of " $n$ " cycle respectively for capacitance $[\mathrm{F}]$ and ESR $[\Omega]$.

If the voltage and temperature were the only parameters that affect the ageing of supercapacitors, using extrapolation, we could predict the lifetime of components with cycling. The extrapolation could predict the life of components when they are solicited by current. Cycling test at given RMS current induce significant heating. Taking into account this temperature rise in the calendar ageing law reduces significantly the estimated lifetime but don't give realistic time.

Our aim is to show that the "equivalent calendar degradation" law underestimates the degradation observed during cycling. To validate this approach, the most critical temperature was used to evaluate the "equivalent calendar degradation". This temperature corresponds to core temperature $\left(\theta=\theta_{\mathrm{h}}\right.$ in (14) and (15)). The core temperature was determined by simulating the thermal model in Fig. 4 for all components for a given cycling.

The next paragraph shows that equations (14) and (15) strongly minimize the degradation of supercapacitors when they are subjected to cycling power. 


\section{RESULTS PRESENTATION FOR THE PACK 5}

This paragraph focuses on the results obtained on a single cycling test to explain and illustrate the used method and to show how a speed factor could be extracted from the results. The variables used to estimate the equivalent calendar degradation are presented. The Pack 5 was solicited, in less than 15 days, to approximately 30000 cycles of charge/discharge at constant power of $2600 \mathrm{~W}$ with a break time of $12.4 \mathrm{~s}$ between each phase in a climatic chamber at 10 ${ }^{\circ} \mathrm{C}$ (Table I).

Fig. 6 shows the individual voltages for 4 supercapacitors for the $200^{\text {th }}$ and $30000^{\text {th }}$ cycle. Fig. 7 and Fig. 8 indicate the evolution of the effective current and the average terminals temperature (measured) and cores temperature (simulated) of 4 supercapacitors as a function of the number of cycles.

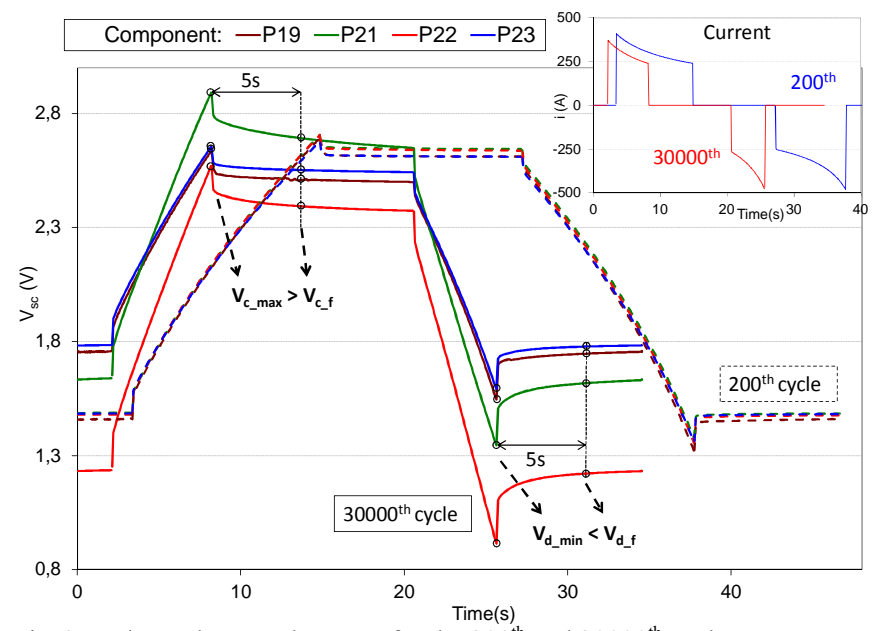

Fig 6: Pack 5 voltage and current for the $200^{\text {th }}$ and $30000^{\text {th }}$ cycle.

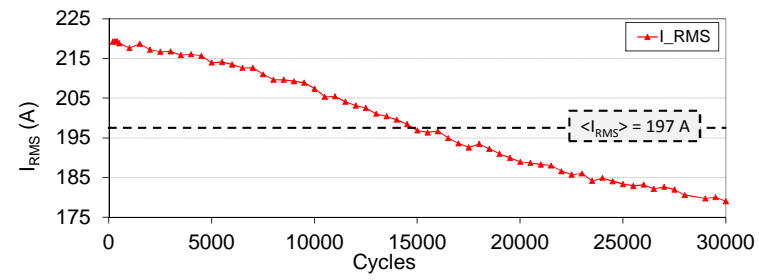

Fig 7: RMS current as a function of the number of cycles

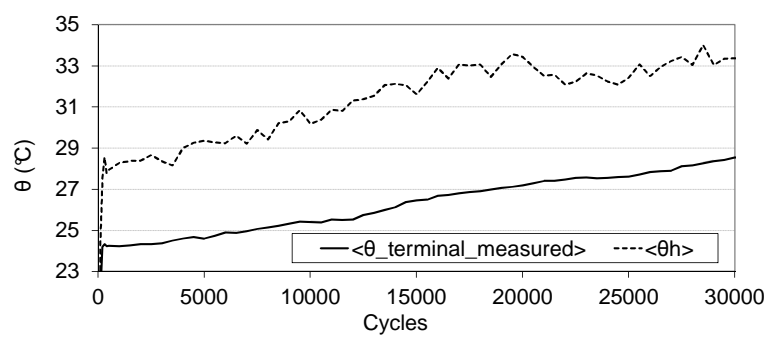

Fig 8: Average value of core components temperature (measured and simulated) as a function of the number of cycles

The loss of capacity and the increase of ESR logically make the charging/discharging time lower. As a result, the effective current decreases during ageing. Its average value over the entire cycling $\left(<\mathrm{I}_{\mathrm{RMS}}>\right)$ is $197 \mathrm{~A}$. In spite of the reduction of the RMS current, the increase of the ESR results in an increase of temperature of the components.
The representative data of a pack is obtained by averageing the results. So the parameters $\left.\left\langle\mathrm{C}_{0}\right\rangle,\left\langle\mathrm{C}_{\mathrm{m}}\right\rangle,\left\langle\mathrm{C}_{\mathrm{deg}}\right\rangle<\mathrm{R}_{0}\right\rangle,\left\langle\mathrm{R}_{\mathrm{m}}\right\rangle$ and $\left\langle\mathrm{R}_{\mathrm{deg}}\right\rangle$ are the average of four individual parameters corresponding to 4 supercapacitors constituting the pack. Average degradations observed for the Pack 5 for both capacitance $\left(<\mathrm{C}_{\mathrm{m}}>\right)$ and ESR $\left(<\mathrm{R}_{\mathrm{m}}>\right)$ with respect to the number of cycle are shown respectively in Fig. 9 and Fig. 10. The "equivalent calendar degradation" law completely underestimates the ageing and must be multiplied by a factor $<\mathrm{K}>$ to equalize the estimated degradation to those observed at the end of cycling:

$$
\begin{aligned}
& <K c>=\frac{<C_{m}(n)>-<C_{0}>}{<C_{\mathrm{deg}}(n)>} \\
& <K r>=\frac{<R_{m}(n)>-<R_{0}>}{<R_{\mathrm{deg}}(n)>}
\end{aligned}
$$

with $\langle\mathrm{Kc}>$ and $\langle\mathrm{Kr}\rangle$ respectively the multiplication factor to equalize the "estimated calendar degradation" of capacitance and ESR with the observed degradation during the cycling test.

The observed evolutions of $\left\langle\mathrm{C}_{\mathrm{m}}>\right.$ and $\left\langle\mathrm{R}_{\mathrm{m}}>\right.$ during cycling are very close to the following equations "estimated calendar degradation" multiplied by the speed factor $(<\mathrm{Kc}>$ or $\langle\mathrm{Kr}>)$ :

$$
\begin{aligned}
& <K c \cdot \operatorname{Cest}(n)>=<C_{0}>+<K c>\times<C_{\mathrm{deg}}(n)> \\
& <K r \cdot \operatorname{Rest}(n)>=<R_{0}>+<K r>\times<R_{\mathrm{deg}}(n)>
\end{aligned}
$$

with $<$ Kc.Cest $>$ and $<$ Kr.Rest $>$ respectively estimated capacitance and equivalent series resistance with their "calendar equivalent degradation" multiply by their speed factor respectively $<\mathrm{Kc}>$ and $\langle\mathrm{Kr}>$.

The factors $\langle\mathrm{Kc}>$ and $\langle\mathrm{Kr}>$ are obtained by using average values. Similarly, $<\operatorname{Kc}$. Cest $(\mathrm{n})>$ and $<\operatorname{Kr}$. Rest(n) $>$ are defined with the average parameters injected respectively in (18) and (19). However, all these factors are also calculated individually for each component of each Pack (noted without " $<>$ "). Fig. 9 and Fig. 10 present these curves with the average parameters of Pack 5:

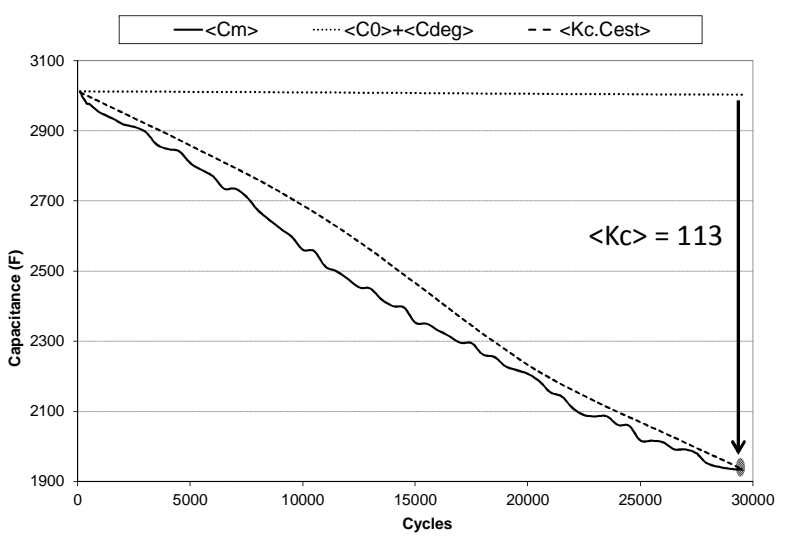

Fig. 9: Comparison of capacitance degradation between measurements $(<\mathrm{Cm}>)$ and estimation of "equivalent calendar degradation" with or without the speed factor $\mathrm{Kc}$ (respectively $<$ Kc.Cest $>$ and $<\mathrm{C} 0>+<\mathrm{Cdeg}>$ ) 


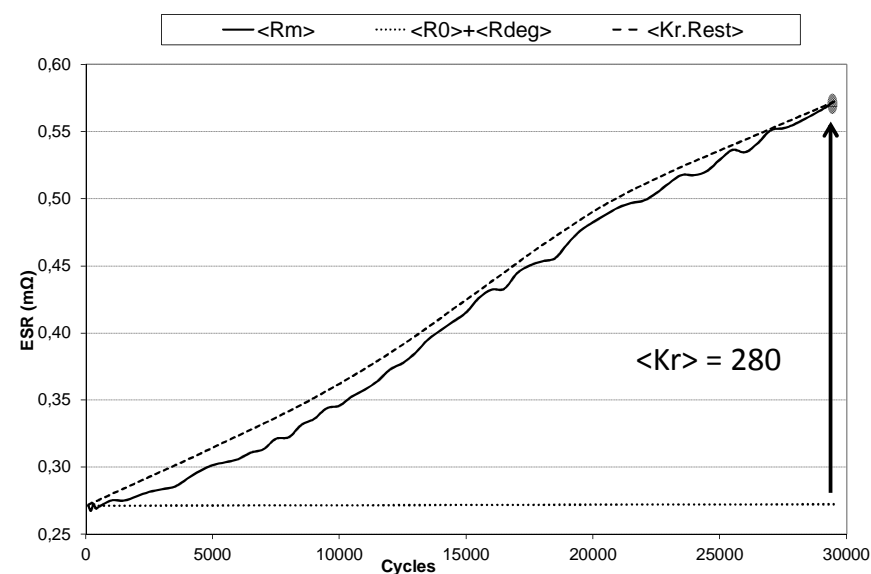

Fig. 10: Comparison of ESR degradation between measurements $(<\mathrm{Rm}>)$ and estimation of "equivalent calendar degradation" with or without the speed factor $\mathrm{Kr}$ (respectively $<\mathrm{Kr}$.Rest $>$ and $<\mathrm{R} 0>+<\mathrm{Rdeg}>$ )

The speed factors $<\mathrm{Kc}>$ and $<\mathrm{Kr}>$ quantify the increase of the degradation rate of components during cycling. The importance of speed factor demonstrates that the degradation during cycling is greater than one calendar ageing test having equivalent voltage / temperature (Table III). The RMS current is intuitively apparent as the more relevant parameters that identify the magnitude of these factors $\mathrm{Kr}$ and Kc. Surely the increase in the rate of degradation could dependent on other quantities such as the current waveform, the amplitude of component heat exchange, the depth of charge/discharge...

In this study, the RMS current through cycling is retained to identify speeds factors $\mathrm{Kc}$ and $\mathrm{Kr}$ that must be applied to "equivalent calendar degradation" in order to represent the real degradation.

\section{DEVELOPMENT OF A NEW AGEING LAW TAKING INTO ACCOUNT THE RMS CURRENT}

The ageing by cycling is much faster than that by calendar ageing even though with lower voltage and temperature. This paragraph proposes to identify the speed factors $(\mathrm{Kc}$ and $\mathrm{Kr}$ ) to be applied (multiplied) on the estimate calendar degradation speed to find the estimate cycling degradation (function of the RMS current). The method described above was applied to each package previously described (see Table I) to obtain a multiplicative speed factor $\langle\mathrm{Kc}\rangle$ and $\langle\mathrm{Kr}\rangle$. Fig. 11 and Fig. 12 , in a semi-logarithmic scale, respectively plot the factors $\langle\mathrm{Kc}\rangle$ and $\langle\mathrm{Kr}\rangle$ of each pack according to RMS current measured during different cycling. For a given test (given RMS current), the vertical bar corresponds to the multiplicative factors of various components of the pack (individual $\mathrm{Kc}$ and $\mathrm{Kr}$ ). Exponential shape is identified on six points. One of these points correspond to calendar ageing $(\operatorname{Irms}=0, \mathrm{~K}=1)$.

From Fig.12, we can deduce that an increase of about 30A to RMS current induce a degradation rate two times greater for ESR. Under these conditions, the lifetime of current cycling is thereby reduced by a factor 2 .

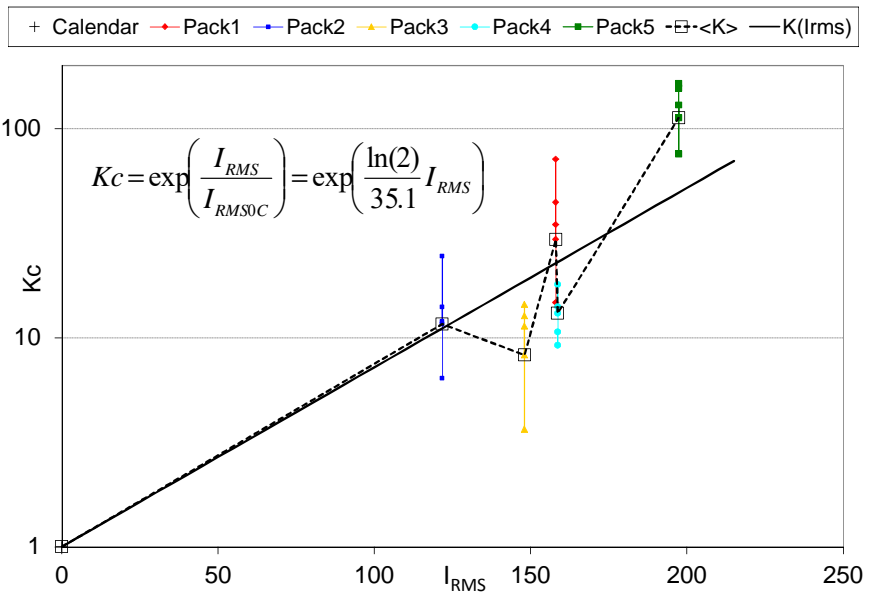

Figure 11: Speed factor of capacitance degradation versus RMS current to applied of the calendar estimation degradation to estimate the degradation during a cycling test

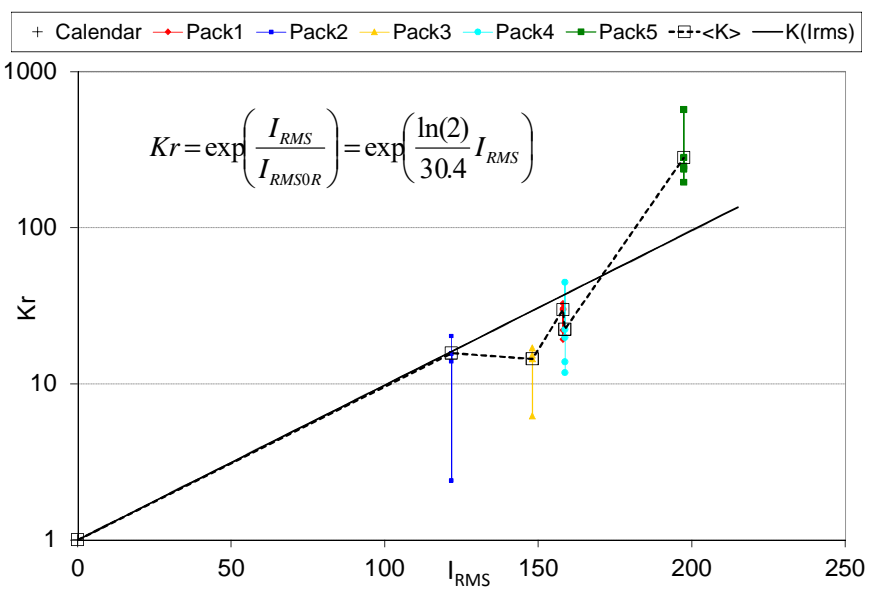

Figure 12: Speed factor of ESR degradation versus RMS current to applied of the calendar estimation degradation to estimate the degradation during a cycling test

In order to integrate the multiplicative factor representing the influence of the RMS current, we propose to use a new equation to estimate the lifetime of supercapacitors:

$$
\tau_{d}\left(V(t) ; \theta(t) ; I_{R M S}\right)=\frac{t_{\text {end }}-t_{\text {init }}}{\frac{1}{\tau_{0}} \int_{t_{\text {init }}}^{t_{\text {end }}} \exp \left(\frac{V(t)}{V_{0}}+\frac{\theta(t)}{\theta_{0}}+\frac{I_{R M S}}{I_{R M S 0}}\right) d t}
$$

with: $I_{R M S 0}=\frac{30}{\ln (2)}[A]$

Equation 20 generalizes Arrhenius law with 3 variables [11]. Figure 13 shows the estimated lifetime versus voltage and RMS current for 3 different temperatures. 


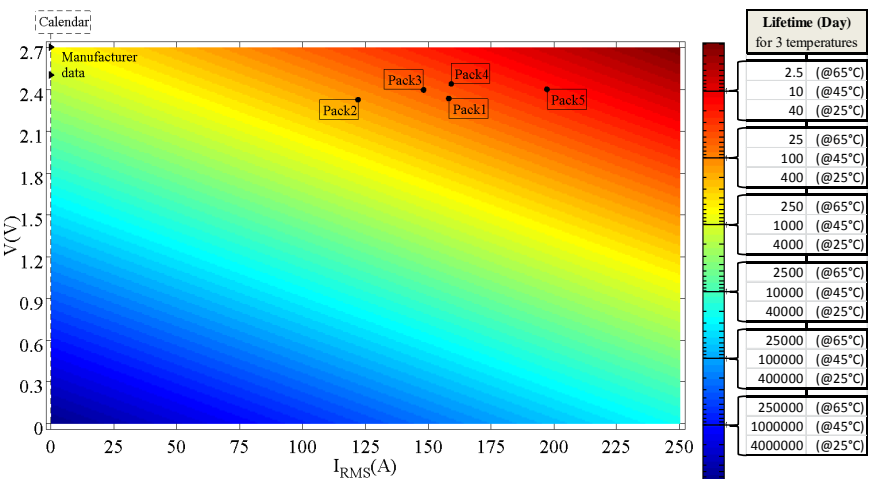

Figure 13: Lifetime estimation according to voltage, RMS current for 3 temperatures

For positioning in Figure 13 the packs studied, their coordinates must be calculated. To do this, the average speed factor due to the voltage $\left\langle\mathrm{K}_{\mathrm{V}}\right\rangle$ is calculated by using the following equation:

$$
<K_{V}>=\frac{1}{t_{\text {end }}-t_{\text {init }}} \int_{t_{\text {init }}}^{t_{\text {end }}} \exp \left(\frac{V(t)}{V_{0}}\right) d t
$$

This factor $\left\langle\mathrm{K}_{\mathrm{V}}>\right.$ allows the deduction of equivalent voltage $\mathrm{V}_{\text {eq }}$ as following:

$$
V_{e q}=V_{0} \ln \left(<K_{V}>\right)
$$

This equivalent voltage $\mathrm{V}_{\text {eq }}$ generates a voltage speed factor equal to the average observed during the cycling. However, the calculated coordinates are not strictly positioned each pack on its estimated lifetime because the average of a product is not equal to the product of the average (see equation (20)).

Table IV compares estimated lifetime by considering equation (10) and equation (20) with the lifetime observed during the cycling test for each Pack.

\begin{tabular}{|c|c|c|c|c|c|c|c|}
\hline \multicolumn{2}{|c|}{ Lifetime (Day) } & Pack & Pack & Pack & Pack & Pack & Calendar: \\
\hline \multirow{2}{*}{ Estimated } & without $I_{R M S}$ & 198 & 863 & 707 & 1057 & 3156 & 1236 \\
\hline & with $I_{\text {RMS }}$ & 5.13 & 51.8 & 23.2 & 27.1 & 33.1 & 1236 \\
\hline \multicolumn{2}{|c|}{ Observed during cycling } & 2.4 & 59.3 & 26.6 & 25.0 & 8.2 & $1220^{c}$ \\
\hline
\end{tabular}

TABLE IV. ESTIMATED AND OBSERVED LIFETIME

The table IV shows that the estimated lifetime that takes into account the RMS current is more realistic than the other estimation which only uses both voltage and temperature to deduce the lifetime.

\section{CONCLUSION}

The study presented in this paper shows that the degradation rate in cycling ageing test is much higher than that expected by calendar ageing with equivalent voltage and temperature. To take into account this difference, the law deduced from calendar ageing was modified. An additional term corresponding to the current function is added to make this law more accurate in cycling test.

Regeneration occurs on components after stopping the cycling $[10 ; 19]$. This regeneration allows components to recover a significant part of their characteristics. These regeneration characteristics have been the subject of other research studies in our laboratory to [20].

\section{ACKNOWLEDGMENT}

\section{REFERENCES}

[1] G. Alcicek, H. Gualous, P. Venet, and R. Gallay, "Experimental study of temperature effect on ultracapacitor ageing," in EPE, Aalborg, 2007.

[2] R Kotz, P Ruch, and D Cericola, "Aging and failure mode of electrochemical double layer capacitors during accelerated constant load tests," Journal of power sources, vol. 195, no. 3, pp. 923-928, 2010.

[3] Linzen, D.; Buller, S.; Karden, E.; De Doncker, R.W., "Analysis and evaluation of charge-balancing circuits on performance, reliability, and lifetime of supercapacitor systems," Industry Applications, IEEE Transactions on, vol.41, no.5, pp.1135,1141, Sept.-Oct. 2005

[4] J. Kowal, D. Uwe Sauer, O. Bohlen, "Ageing behaviour of electrochemical double layers capacitors" part I. Experimental study and ageing mode," Journal of power sources, vol. 172, no. 1, pp. 468-475, 2007.

[5] O. Bohlen, J. Kowal, D. U. Sauer: "Ageing behaviour of electrochemical double layer capacitors Part II. Lifetime simulation model for dynalic applications" Journal of Power Sources 173, 2007

[6] El Brouji, E.-H.; Briat, O.; Vinassa, J. -M; Bertrand, N.; Woirgard, E., "Impact of Calendar Life and Cycling Ageing on Supercapacitor Performance," Vehicular Technology, IEEE Transactions on , vol.58, no.8, pp.3917,3929, Oct. 2009

[7] H. El Brouji, O. Briat, J-M. Vinassa, N. Bertrand, and E. Woirgard, "Comparison between changes of ultracapacitors model parameters during calendar life and power cycling ageing tests," Microelectronics and reliability, vol. 48, no. 8-9, pp. 1473-1478, 2008.

[8] H. El Brouji, O. Briat, J-M. Vinassa, N. Bertrand, and E. Woirgard, "Ageing quantification of ultracapacitors during calendar life and power cycling tests using a physically-based impedance model," in ESSCAP08, Rome, 2008.

[9] Veit, B.; Hempel, T.; Pohl, A.; Bodach, M., "Investigations on life estimation of ultracapacitors using time domain methods," Systems, Signals and Devices (SSD), 2012 9th International Multi-Conference on , vol., no., pp.1,4, 20-23 March 2012

[10] El Brouji, H.; Vinassa, J.-M.; Briat, O.; Lajnef, W.; Bertrand, N.; Woirgard, E., "Parameters evolution of an ultracapacitor impedance model with ageing during power cycling tests," Power Electronics Specialists Conference, 2008. PESC 2008. IEEE, vol., no., pp.4624,4629, 15-19 June 2008

[11] Hijazi, A.; Kreczanik, P.; Bideaux, E.; Venet, P.; Clerc, G.; Di Loreto, M., "Thermal Network Model of Supercapacitors Stack," Industrial Electronics, IEEE Transactions on , vol.59, no.2, pp.979,987, Feb. 2012

[12] Gualous, H.; Louahlia-Gualous, H.; Gallay, R.; Miraoui, A., "Supercapacitor Thermal Modeling and Characterization in Transient State for Industrial Applications," Industry Applications, IEEE Transactions on , vol.45, no.3, pp.1035,1044, May-june 2009

[13] Product Guide-. [Online]. HYPERLINK "http://www.maxwell.com/ " Site officiel de Maxwell , 2009.

[14] EPCOS, « UltraCapTM double layer capacitors - A new energy storage device for peak power applications », Product Profile, 2002.

[15] P. Kreczanik, T. Kovaltchouk, A. Hijazi, P. Venet, G. Clerc "Consideration of the ageing in the control of the balancing circuit of supercapacitor" in ESSCAP, Bordeaux, 2010. 
[16] D Linzen, S Buller, E Karden, and R De doncker, "Analysis and Evaluation of Charge-Balancing Circuits on Performance, Reliability, and Lifetime of Supercapacitor Systems," IEEE transactions on industrial applications, vol. 41, no. 5, pp. 1135- 1141, 2005.

[17] National Institute of Standards and Technolog (NIST) "Engineering statistics handbook" http://www.itl.nist.gov/div898/handbook/apr/section1/apr151.htm (or apr152.htm)
[18] Maxwell technologies: "Application note, life duration estimation», http://www.maxwell.com

[19] Chaari, R.; Briat, O.; Deletage, J.Y.; Vinassa, J., "Performances regeneration of supercapacitors during accelerated ageing tests in power cycling," Power Electronics and Applications (EPE 2011), Proceedings of the 2011-14th European Conference on , vol., no., pp.1,7, Aug. 30 2011-Sept. 12011

[20] PhD thesis, 2011 